\title{
Direct Growth of Carbon Nanotubes on Aluminum Foil by Atmospheric Pressure Microwave Plasma Chemical Vapor Deposition
}

\author{
Dashuai Li (D) and Ling Tong *(D) \\ School of Automation Engineering, University of Electronic Science and Technology of China, \\ Chengdu 611731, China; 201511070102@std.uestc.edu.cn \\ * Correspondence: tongling@uestc.edu.cn; Tel.: +86-180-8006-5381
}

Citation: Li, D.; Tong, L. Direct Growth of Carbon Nanotubes on Aluminum Foil by Atmospheric Pressure Microwave Plasma Chemical Vapor Deposition. Processes 2021, 9, 36. https://doi.org/10.3390/ pr9010036

Received: 13 November 2020 Accepted: 23 December 2020 Published: 25 December 2020

Publisher's Note: MDPI stays neutral with regard to jurisdictional claims in published maps and institutional affiliations.

Copyright: (c) 2020 by the authors. Licensee MDPI, Basel, Switzerland. This article is an open access article distributed under the terms and conditions of the Creative Commons Attribution (CC BY) license (https: / / creativecommons.org/ licenses/by/4.0/).

\begin{abstract}
This paper is about the research that carbon nanotubes (CNTs) grow on aluminum foils without additional catalysts by atmospheric pressure microwave plasma chemical vapor deposition (AMPCVD) with the precursor of argon-hydrogen-ethanol. At different temperatures, a series of experiments that CNTs grow on aluminum foils were done with and without the alumina layer. The EDS results showed that iron impurities in aluminum foils catalyze the growth of CNTs. By measurements of SEM and HRTEM, tens of microns long and multi-walled CNTs are grown. The CNTs' content in the sample changes more with the increase in temperature. The Raman measuring shows that CNTs have fewer defects with higher temperature. Finally, by measurements of EDS mapping and XRD on aluminum foil, the growth mechanism of CNTs was discussed.
\end{abstract}

Keywords: microwave plasma; AMPCVD; CNTs; aluminum foil

\section{Introduction}

Carbon nanotubes (CNTs) have become one of the most interesting materials since Iijima synthesized them by the arc-discharge process in 1991 [1] because of their novel hollow-tube structure, nanometer dimensions, high specific surface area, excellent mechanics, electricity, and chemistry performance. To date, the typical techniques for synthesizing CNTs are those based on catalyst-assisted chemical vapor deposition (CVD) [2-6]. In order to improve the growth rate of nanomaterials and reduce the growth temperature, lowpressure plasma-enhanced chemical vapor deposition (PECVD) [7-10] has been developed. The effective catalysts are iron-family elements, including iron, cobalt, nickel, and their alloys [11,12]. The catalysts used to grow CNTs are commonly nanoparticles, colloidal particles, or solutions of catalyst precursors, and most of the catalyst deposition methods operate under vacuum and require specified equipment for vacuum delivery [13].

Thus, many studies have synthesized CNTs on materials containing iron, cobalt, and nickel as substrates, such as stainless steel [14,15] and mica [16]. However, the morphology and diameter of CNTs grown on stainless steel cannot be effectively controlled because there are no uniform nanoparticles on the substrate to catalyze their growth. About $1.8 \%$ of iron oxide $\left(\mathrm{Fe}_{2} \mathrm{O}_{3}\right)$ uniformly disperses in the mica sheet, which can catalyze CNTs' growth at high temperatures. However, the iron in mica-sheet content is low, and all of it is iron oxide, which requires high temperatures to catalyze CNTs. We found that commercial aluminum foil contains about $4-5 \%$ iron, which may be used as a substrate for the growth of CNTs.

Commercial aluminum foil has excellent electrical conductivity, is lightweight and flexible, has corrosion resistivity and a lower price, and is an available material, making it one of the most appropriate flexible substrates [17]. CNTs grown on the aluminum foil surface are ideal, flexible capacitor material, and are of enormous interest for a wide range of applications such as display, sensors, wearable electronics, etc. [17-19]. The typical 
way to grow CNTs on aluminum foil by CVD is to deposit a metal catalyst layer on the aluminum foil surface, such as Co or Fe [20-23]. The methods to deposit catalysts are physical vapor deposition, electroplating, and spin coating, etc., limiting the large-scale synthesis of CNTs on the aluminum foil and their application. In our previous study [14], atmospheric pressure microwave plasma chemical vapor deposition (AMPCVD) proved to be a useful nanomaterial synthesis technique. Because the atmospheric pressure microwave plasma and the tube furnace work independently, AMPCVD can increase the growth rate without reducing the quality of the CNTs grown on the stainless steel substrate.

This paper reports a simple and economical procedure for the direct growth of CNTs on commercial aluminum foil without any additional catalyst, using ethanol vapor as the carbon source by AMPCVD at $600-900{ }^{\circ} \mathrm{C}$. The CNTs' growth on aluminum foil with and without the oxide layer at different temperatures was analyzed, and the growth mechanism was discussed. We remind readers that this is the only study of CNTs' growth on aluminum foil without additional catalysts.

\section{Experiment}

Figure 1 shows the schematic diagram of the AMPCVD. A coaxial microwave plasma generator was used to produce an atmospheric pressure microwave plasma with $200 \mathrm{~W}$ power, completely decomposing the ethanol precursor into $\mathrm{CH}, \mathrm{C}_{2}$, and $\mathrm{HO}$ groups. These carbon-containing groups reacted with catalysts on the substrate to grow CNTs at a suitable temperature provided by the tube furnace with $\mathrm{a} \pm 1^{\circ} \mathrm{C}$ temperature accuracy. The addition of atmospheric pressure microwave plasma technology enhanced the decomposition ability of the CVD precursor. At the same time, it retained the advantages of CVD technology, such as accurate growth temperature, a large growth area for nanomaterials, and a wide pressure range. These characteristics made the nanomaterials grown by AMPCVD under the same substrate and temperature have a higher growth rate with a similar defect concentration compared with CVD.

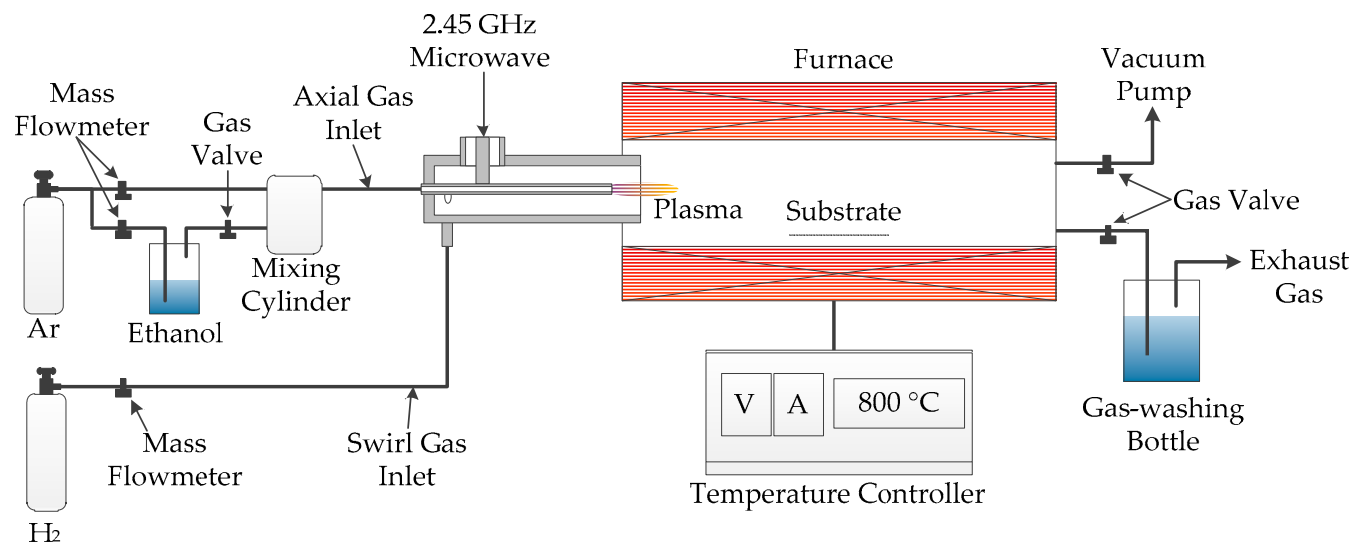

Figure 1. The diagram of atmospheric pressure microwave plasma chemical vapor deposition (AMPCVD) for carbon nanotubes' (CNTs) growth on aluminum foil with the ethanol precursor.

In the experiment, to understand the effect of the alumina layer on the growth of CNTs, the commercial aluminum foil and the aluminum foil with an oxide layer removed by acid treating were used as the substrates for CNTs' growth. The carbon source was produced by $100 \mathrm{sccm}$ (standard cubic centimeter per minute) argon (99.999\%, JND Gas Co. Ltd, Chengdu, China) bubbling $10 \mathrm{~mL}$ ethanol (99.7\%, Chron Chemicals, Chengdu, China) at $30^{\circ} \mathrm{C}$. During the growth of CNTs, the gas flow of the axial gas inlet was $800 \mathrm{sccm}(100 \mathrm{sccm}$ ethanol vapor and $700 \mathrm{sccm}$ argon), and the swirling gas was $200 \mathrm{sccm}$ hydrogen $(99.999 \%$, JND Gas Co. Ltd., Chengdu, China). The CNTs' growth temperatures of 500, 600, 700, 800, and $900{ }^{\circ} \mathrm{C}$ were investigated because the growth-temperature range of CNTs on stainless steel substrates is $500-900{ }^{\circ} \mathrm{C}$ by AMPCVD. 
Aluminum foils were cleaned using acetone and ethanol with 10 min sonication, followed by rinsing with deionized water. One of the cleaned substrates was immersed in $1 \mathrm{M}$ aqueous hydrochloric $(\mathrm{HCl}$, Chron Chemicals, Chengdu, China) for $1 \mathrm{~min}$ and rinsed with deionized water (Chron Chemicals, Chengdu, China) to remove its oxide layer, while the other one was not treated. Both substrates were dried at $60^{\circ} \mathrm{C}$ for $10 \mathrm{~min}$ and placed in the quartz tube (diameter: $52 \mathrm{~mm}$, length: $600 \mathrm{~mm}$ ) of the AMPCVD reactor (Laboratory self-built). Firstly, we used a vacuum pump to empty the air in the quartz tube. Then, we swirled $200 \mathrm{sccm}$ hydrogen into the reactor until the pressure in the quartz tube was raised to the atmosphere, and we turned the valve of the gas-washing bottle on. After $120 \mathrm{~min}$ of hydrogen flow, the furnace was heated to the growth temperature, followed by pumping $800 \mathrm{sccm}$ argon to the plasma generator and then exciting plasma. When the furnace temperature was stable, bubbling ethanol was kept at $30^{\circ} \mathrm{C}$ with $100 \mathrm{sccm}$ argon. Then $700 \mathrm{sccm}$ argon and $100 \mathrm{sccm}$ ethanol-vapor mixture gas were pumped into the AMPCVD through the plasma for CNT growth. Finally, after 10 min growth process of CNTs, we turned the system off. When the furnace cooled down to room temperature under the hydrogen environment, the CNTs were prepared on the aluminum foils.

The CNTs grown on the substrate can be measured directly by SEM, EDS, XPS, Raman, and XRD. TEM samples were prepared by sonicating the substrates in ethanol to obtain the CNTs' ethanol dispersion and then dropping them onto a copper grid. Morphology of fabricated CNTs on aluminum foil was studied using Scanning Electron Microscopy (SEM; Hitachi S-5000 20 kV, Tokyo, Japan) and Transmission Electron Microscope (TEM; FEI Tecnai G2 F20 $200 \mathrm{kV}$, Hillsboro, OR, USA). The chemistry of the CNTs and the substrates were examined using energy dispersive spectroscopy (EDS; attached to the Hitachi S-5000, Tokyo, Japan) and X-ray photoelectron spectroscopy (XPS; Thermo Fisher Escalab Xi+, Waltham, MA, USA). A qualitative analysis of the grown CNTs was performed by Raman spectroscopy (LabRAM; HR Evolution Horiba, Kyoto, Japan) at $532 \mathrm{~nm}$ wavelength. X-ray diffraction (XRD; Bruker D8 Advance A25X, Karlsruhe, German) and a Field emission scanning electron microscope (FESEM; FEI Inspect F50, Hillsboro, OR, USA) were adopted to analyze the structure of iron impurity dispersed in aluminum foil.

\section{Experiment Results and Discussion}

\subsection{CNTs Grown on the Aluminum Foil with an Oxide Layer}

Figure 2 shows the aluminum foil after the CNT formation process at 600, 700, 800, and $900{ }^{\circ} \mathrm{C}$. At the temperature of $600^{\circ} \mathrm{C}$, the aluminum foil shows no apparent change, indicating the aluminum foil does not melt. Small wrinkles appear on the substrate surface at $700{ }^{\circ} \mathrm{C}$, indicating that the aluminum foil begins to melt. The substrate surface wrinkles and the color changes from silver to yellow and gray at 800 and $900{ }^{\circ} \mathrm{C}$, indicating that the aluminum foil melts at both temperatures.

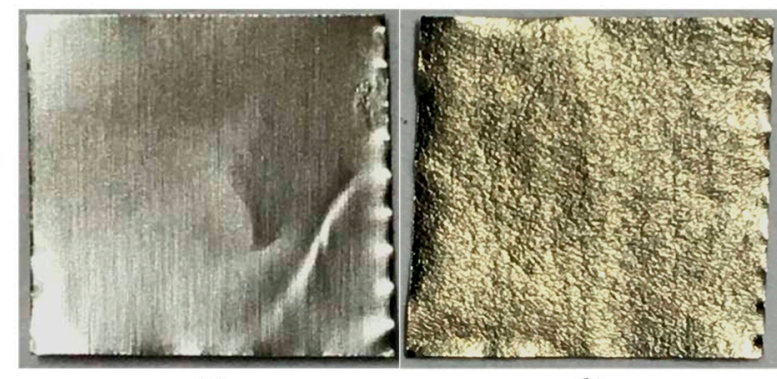

(a) (b)

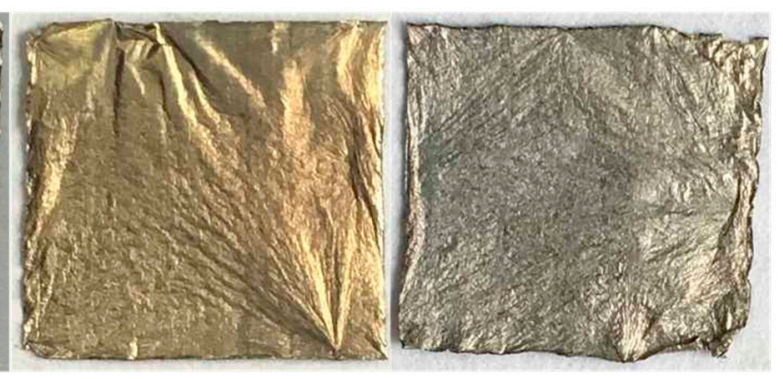

(c) (d)

Figure 2. The photos of the aluminum foil substrates after the CNT formation process at (a): 600, (b): 700, (c): 800 , and (d): $900{ }^{\circ} \mathrm{C}$.

CNTs cannot grow on the aluminum foil at $500{ }^{\circ} \mathrm{C}$; they can grow on the edge at 600-900 ${ }^{\circ} \mathrm{C}$, shown in Figure 3a-d, and grow on the oxide layer surface at 800 and $900{ }^{\circ} \mathrm{C}$, shown in Figure $3 \mathrm{e}, \mathrm{f}$. The CNTs that grew on the surface and the edge at the same 
temperature have an extremely similar structure. The CNTs are disordered orientations, and their length at all temperatures is about tens of micrometers. The density of CNTs grown on the surface at $900{ }^{\circ} \mathrm{C}$ is much higher than that at $800{ }^{\circ} \mathrm{C}$, and the $\mathrm{CNTs}$ on the edge show no difference at all temperatures.

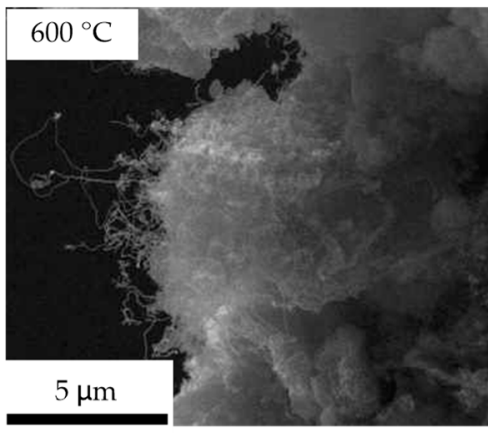

(a)

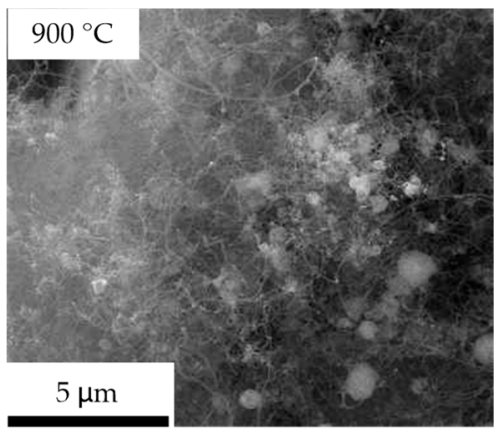

(d)

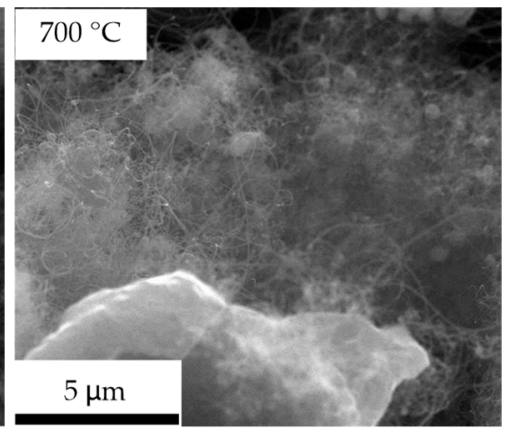

(b)

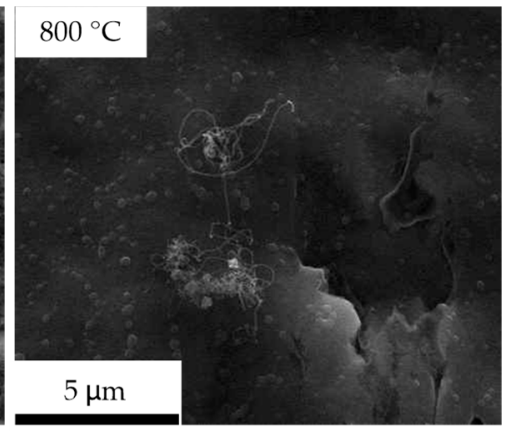

(e)

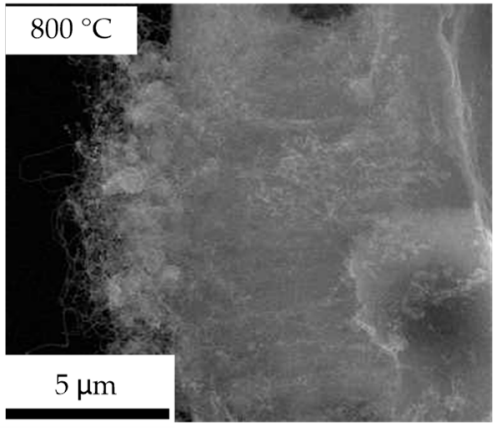

(c)

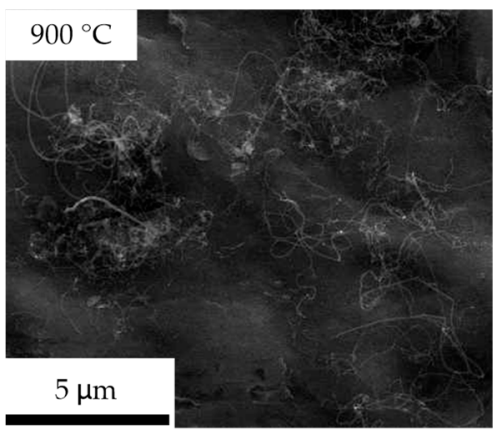

(f)

Figure 3. The SEM micrographs of the CNTs obtained at $600,700,800$, and $900{ }^{\circ} \mathrm{C}$ on the aluminum foil. (a-d) is the CNTs grown on the edge at $600,700,800$, and $900{ }^{\circ} \mathrm{C} ;(\mathbf{e}, \mathbf{f})$ is the CNTs grown on the surface at 800 and $900{ }^{\circ} \mathrm{C}$.

Figure 4 shows the HRTEM micrographs of CNTs grown at $600-900{ }^{\circ} \mathrm{C}$ ethanol dispersions dropped on a copper grid; their thickness and layer distances were measured, as shown in Figure 4e-h. Figure 4a,e shows the micrographs of the CNTs grown at $600{ }^{\circ} \mathrm{C}$, with a lot of carbon layer stacking faults in the wall of the CNTs. The discontinuous carbon layer of the wall at $600{ }^{\circ} \mathrm{C}$ is due to the low catalyst nanoparticles' activity at $600{ }^{\circ} \mathrm{C}$, resulting in a weak carbon-dissolving and precipitating ability. The $\mathrm{CNTs}^{\prime}$ walls grown at 700,800 , and $900^{\circ} \mathrm{C}$ are composed of tightly aligned graphite sheets with a layer distance of $0.34 \mathrm{~nm}$. The content of amorphous carbon attached to CNTs decreases with the increase in temperature, contributing to an increased quality of the CNTs. Figure $4 \mathrm{~d}-\mathrm{h}$ shows the CNT grown at $900{ }^{\circ} \mathrm{C}$; its surface is smooth, and the carbon layer of the CNT is uniform and tight. Figure $4 \mathrm{i}-1$ shows the diameter distribution of CNTs grown on the aluminum foil at $600-900{ }^{\circ} \mathrm{C}$. The results show that the diameters of CNTs grown at $600,700,800$, and $900{ }^{\circ} \mathrm{C}$ are $10-20,14-22,16-26$, and $22-47 \mathrm{~nm}$, respectively, and increase gradually with the increase in temperature. The narrow diameter distribution and uniform density contribute to the uniformly disperse distribution and size of catalyst nanoparticles in commercial aluminum foil. 


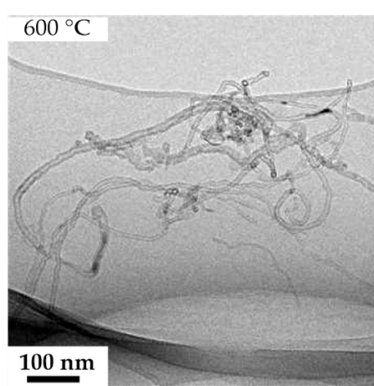

(a)
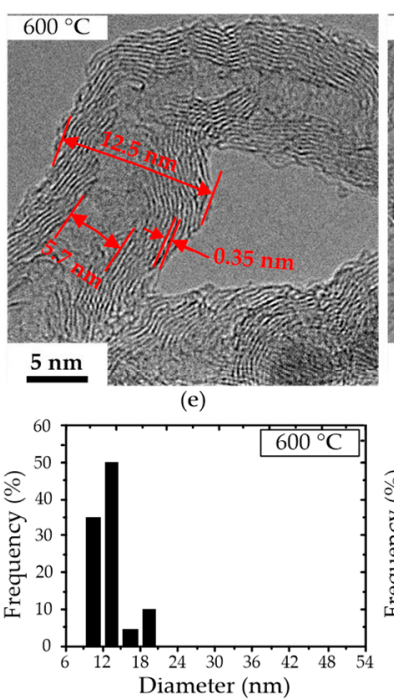

(i)

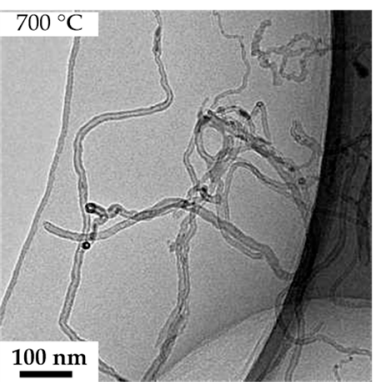

(b)

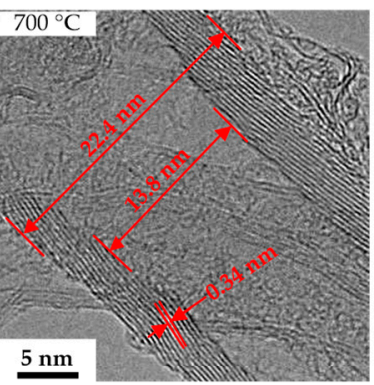

(f)

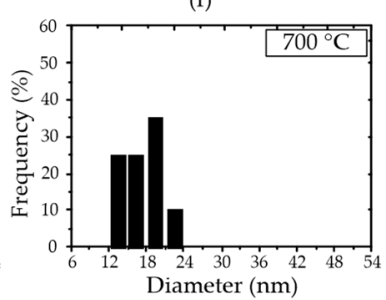

(j)

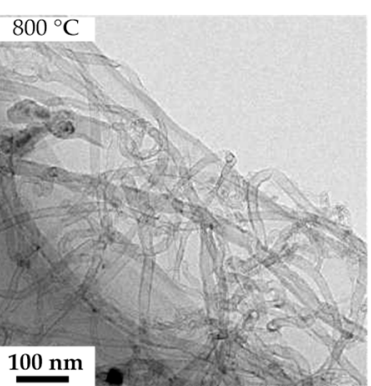

(c)

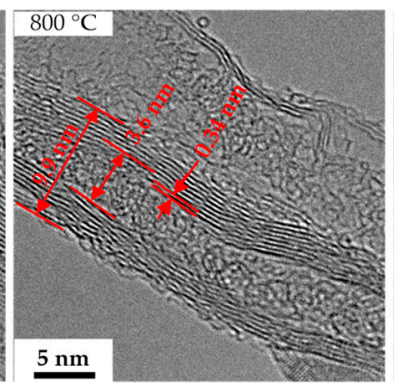

(g)

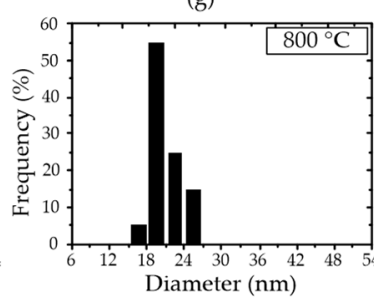

(k)

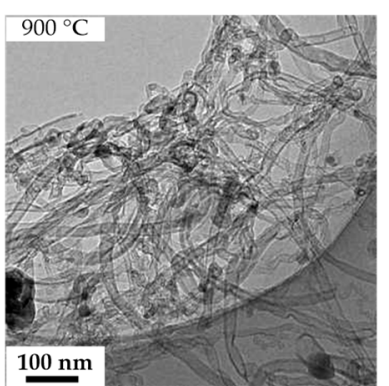

(d)

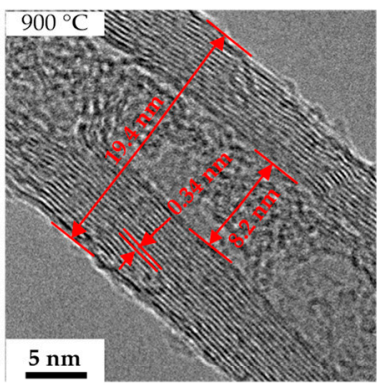

(h)

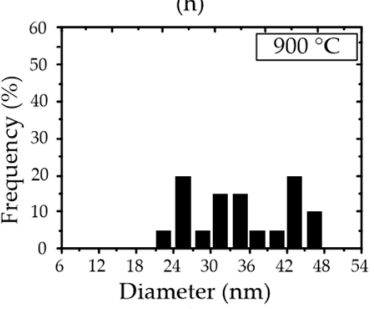

(l)

Figure 4. HRTEM images of CNTs grown on the aluminum foil at $600,700,800$, and $900{ }^{\circ} \mathrm{C}$. (a-d): low-magnification images; (e-h): high-magnification images; (i-1): the diameter distribution of CNTs in $(\mathbf{a}-\mathbf{d})$.

The EDS spectra are shown in Figure 5, confirming the presence of oxygen, silicon, and iron in addition to carbon and aluminum. It is speculated that the high amount of oxygen present in the sample is due to the oxide layer of the aluminum foil. The EDS spectra give evidence that the iron impurity in the aluminum foil catalyzed the growth of CNTs because the elements of silicon and aluminum normally cannot catalyze the CNTs' growth. In order to ensure that it is iron impurity acting as the catalyst, a high-purity aluminum foil was used as a substrate to grow CNTs at $800^{\circ} \mathrm{C}$, but no CNTs grew. We proved that it is the iron impurity in commercial aluminum foil that catalyzed the growth of CNTs.

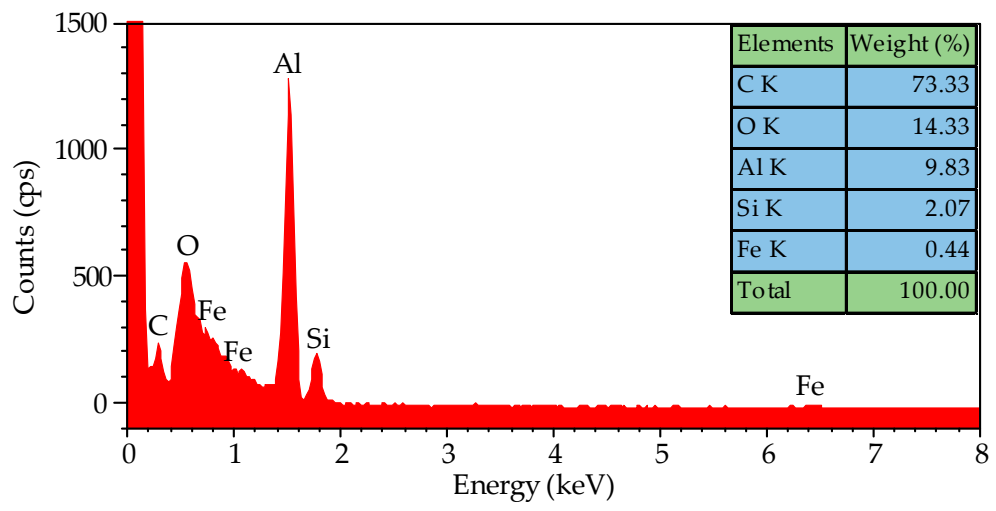

Figure 5. The EDS spectra of the CNTs grown on the aluminum foil at $800{ }^{\circ} \mathrm{C}$, and their amounts of specific elements. 
Figure 6 shows the Raman spectra of the CNTs at $600,700,800$, and $900{ }^{\circ} \mathrm{C}$ grown on the substrates with $532 \mathrm{~nm}$ laser at room temperature. In three Raman spectra of 700, 800 , and $900{ }^{\circ} \mathrm{C}$, two peaks centered at 1336 and $1577 \mathrm{~cm}^{-1}$ were observed, and they are 1336 and $1594 \mathrm{~cm}^{-1}$ at $600{ }^{\circ} \mathrm{C}$. They correspond to the graphitic phase D and G bands, proving the presence of crystalline carbon. The intensity ratio of $D$ peak and $G$ peak $\left(I_{\mathrm{D}} / I_{\mathrm{G}}\right)$ is sensitive to structural defects in the CNTs; the lower the value, the more graphitic the carbon. With the increase of the synthesis temperature, the $\mathrm{D}$ peak narrowed and the $I_{\mathrm{D}} / I_{\mathrm{G}}$ ratio decreased, indicating the increased graphitic crystallinity of the CNTs. The G peak of pure graphite is at $1582 \mathrm{~cm}^{-1}$, and the blue shift of the $\mathrm{G}$ peak of the $\mathrm{CNTs}$ grown at $600{ }^{\circ} \mathrm{C}$ is caused by the high-defect concentration on the samples. The lowest $I_{\mathrm{D}} / I_{\mathrm{G}}$ ratio $(0.71)$ was found for the sample obtained at $900{ }^{\circ} \mathrm{C}$. We can conclude that most graphitic carbon is obtained at $900{ }^{\circ} \mathrm{C}$.

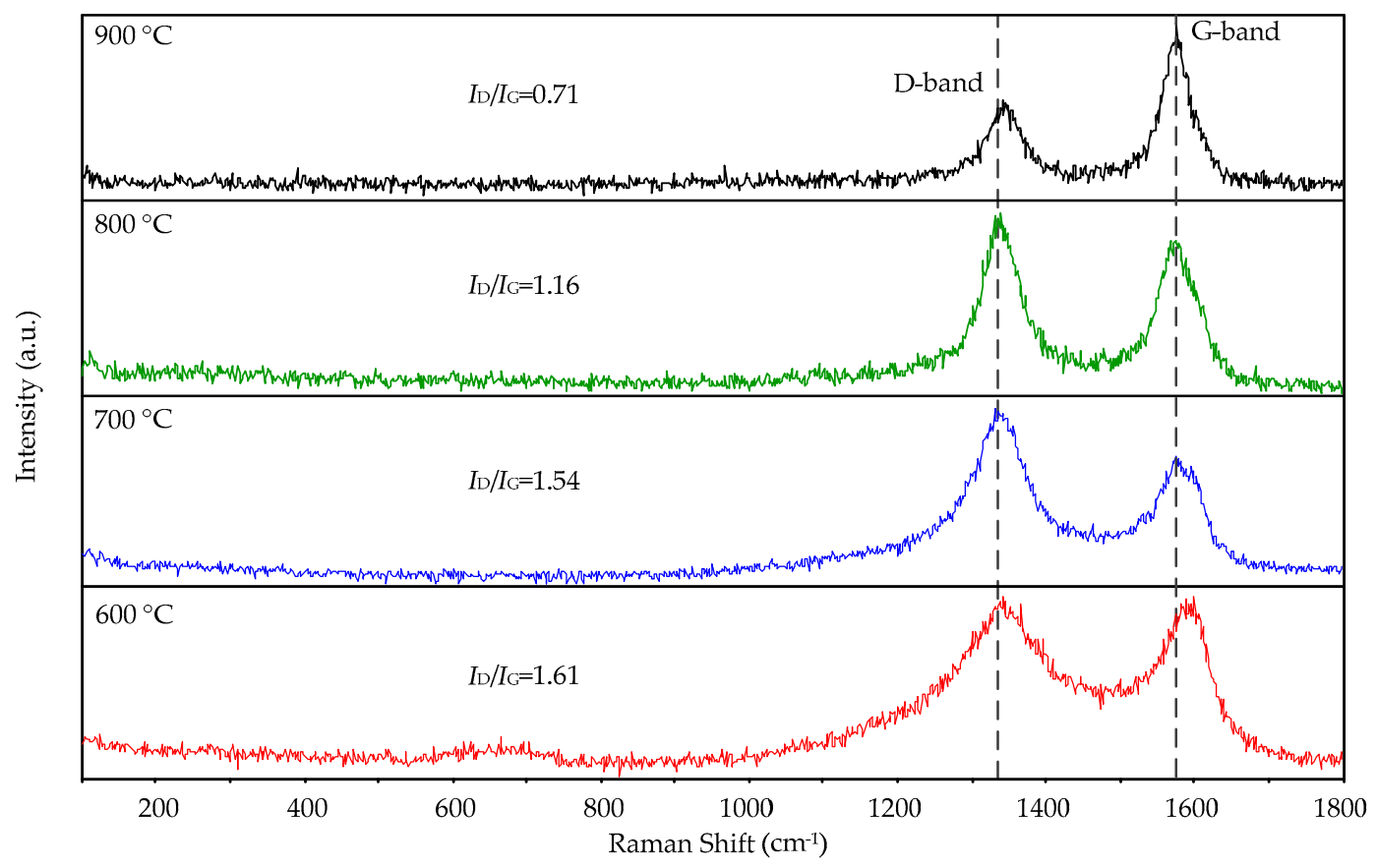

Figure 6. Raman spectra of the CNTs grown on the aluminum foils by the AMPCVD at 600, 700, 800, and $900{ }^{\circ} \mathrm{C}$.

The surface purity of the growth CNTs at $900{ }^{\circ} \mathrm{C}$ was investigated by XPS measurement. The XPS spectra show that the CNTs contain C, O, and N elements, as shown in Figure 7a. Figure $7 \mathrm{~b}$ shows the magnified view of the $\mathrm{C} 1 \mathrm{~s}$ peak, indicating that the main components are $\mathrm{C}-\mathrm{C} / \mathrm{C}=\mathrm{C}(284.6 \mathrm{eV}, 80.46 \%)$, and the surface defects are hydroxyl $(-\mathrm{C}-\mathrm{OH} /-\mathrm{C}-\mathrm{N}, 286.0 \mathrm{eV}, 19.54 \%)$. The hydroxyl groups attached on the CNTs' surface were mainly from the decomposition of the ethanol precursor.

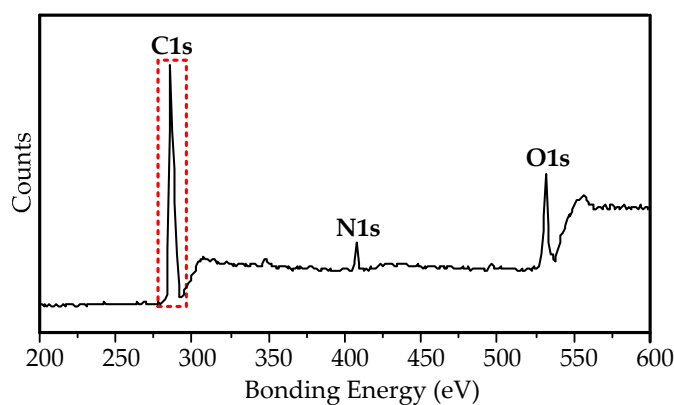

(a)

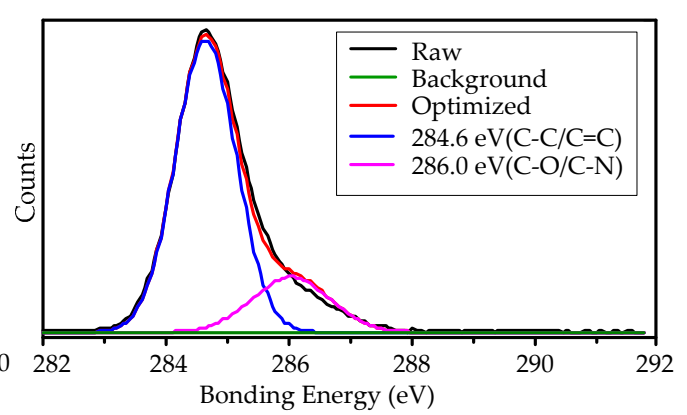

(b)

Figure 7. XPS spectra of the CNTs grown on the aluminum foils by the AMPCVD at $900{ }^{\circ} \mathrm{C}$. (a): the global spectra; (b): the magnification view of $\mathrm{C} 1 \mathrm{~s}$. 


\subsection{CNTs Grown on the Aluminum Foil without an Oxide Layer}

The air oxidizes the aluminum foil to form a dense alumina layer on its surface. To investigate the effect of the alumina layer on the growth of CNTs, we used $\mathrm{HCl}$, treating aluminum foil to remove its oxide layer and then grow CNTs at $600-900{ }^{\circ} \mathrm{C}$. The aluminum foils after the CNT formation process at $600,700,800$, and $900{ }^{\circ} \mathrm{C}$ are shown in Figure 8 . The substrate shows no obvious change at $600{ }^{\circ} \mathrm{C}$, which indicates the aluminum foil does not melt. Small wrinkles appear on the substrate surface at $700{ }^{\circ} \mathrm{C}$, indicating that the aluminum foil begins to melt. The substrates shrink, wrinkle, and change color at 800 and $900{ }^{\circ} \mathrm{C}$, suggesting that the aluminum foil entirely melts with partial evaporation.

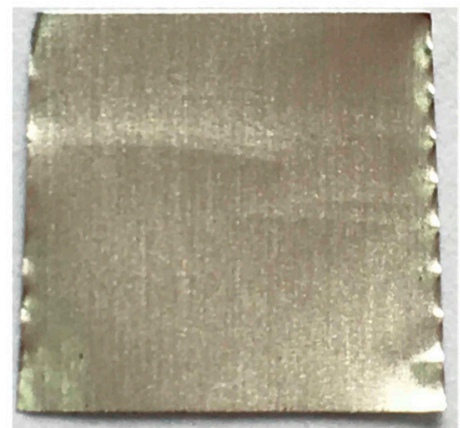

(a)

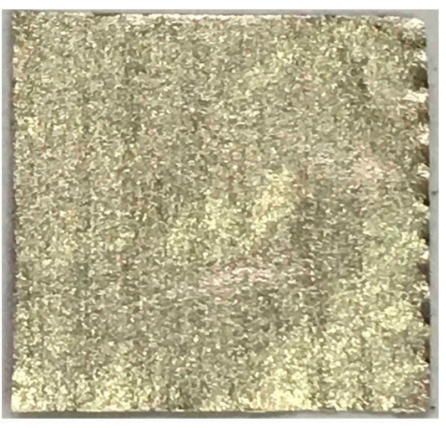

(b)

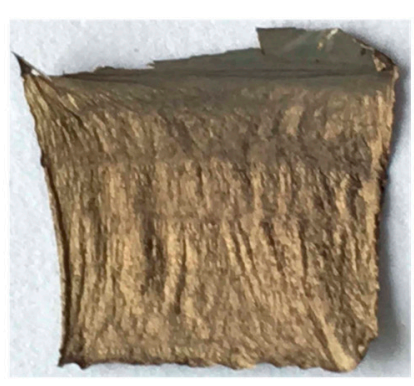

(c)

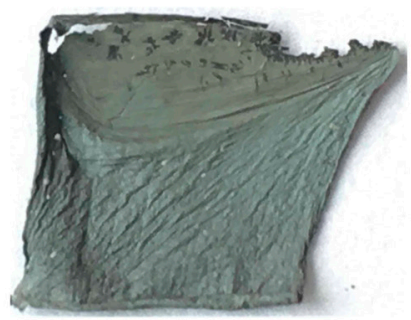

(d)

Figure 8. The photos of the aluminum foil substrates without an oxide layer after the CNT formation process at (a): 600 , (b): $700,(\mathbf{c}): 800$, and (d): $900{ }^{\circ} \mathrm{C}$.

CNTs only grow on the substrate surface at 600 and $700{ }^{\circ} \mathrm{C}$, shown in Figure $9 \mathrm{a}-\mathrm{d}$, and the density of the former is much higher than the latter. The obtained CNTs have disordered orientation, and their length and diameter are $3-10 \mu \mathrm{m}$ and $18-25 \mathrm{~nm}$ at $600{ }^{\circ} \mathrm{C}$, and at $1-5 \mu \mathrm{m}$ and $40-110 \mathrm{~nm}$ at $700{ }^{\circ} \mathrm{C}$. Much amorphous carbon is attached to the surface of the CNTs at $600{ }^{\circ} \mathrm{C}$, as shown by red arrows in Figure 9c.

The Raman spectra of the CNTs grown on the surface of aluminum foil treated by $\mathrm{HCl}$ at 600 and $700{ }^{\circ} \mathrm{C}$ are shown in Figure $9 \mathrm{e}$, and their $I_{\mathrm{D}} / I_{\mathrm{G}}$ ratios are 1.69 and 1.51, respectively. The $\mathrm{D}$ peak and $\mathrm{G}$ peak of the CNTs grown at both temperatures are all centered at 1343 and $1600 \mathrm{~cm}^{-1}$, the blue shift of the $\mathrm{G}$ peak indicating the defection concentration of the CNTs is high, and the broadening of the D peak at $600^{\circ} \mathrm{C}$ is caused by amorphous carbon. Compared with the CNTs grown on the edge of the aluminum foil, the defection concentration of the CNTs grown on the surface is slightly higher at the same temperature. Figure $9 \mathrm{f}$ shows the EDS spectra of the CNTs grown on the aluminum surface at $600{ }^{\circ} \mathrm{C}$. The oxygen weight content has decreased to $1.02 \%$, proving that the $\mathrm{HCl}$ has indeed removed the oxide layer on the aluminum-foil surface.

\subsection{CNTs Growth Mechanism on the Aluminum Foil}

Figure 10a shows the distribution of aluminum, oxygen, and iron on the original aluminum foil surface, and their contents are $87.4 \%, 7.1 \%$, and $5.5 \%$, respectively; the distribution of iron particles is even. Figure 10b shows the XRD spectra of the original aluminum foil-iron oxide $\left(\mathrm{Fe}_{2} \mathrm{O}_{3}\right)$ peak (JCPDS card No. 16-0653) at $16.2^{\circ}(2 \theta)$, ferrous oxide $(\mathrm{FeO})$ peak (JCPDS card No. 06-0615) at $41.9^{\circ}(2 \theta)$, and a trace of iron (Fe) peak (JCPDS card No. 06-06960) at $82.3^{\circ}(2 \theta)$ were observed. The results prove that the iron impurity on the aluminum-foil surface mainly exists in $\mathrm{Fe}_{2} \mathrm{O}_{3}$. However, no $\mathrm{Al}_{2} \mathrm{O}_{3}$ peaks were detected in the XRD spectra for its low content. 


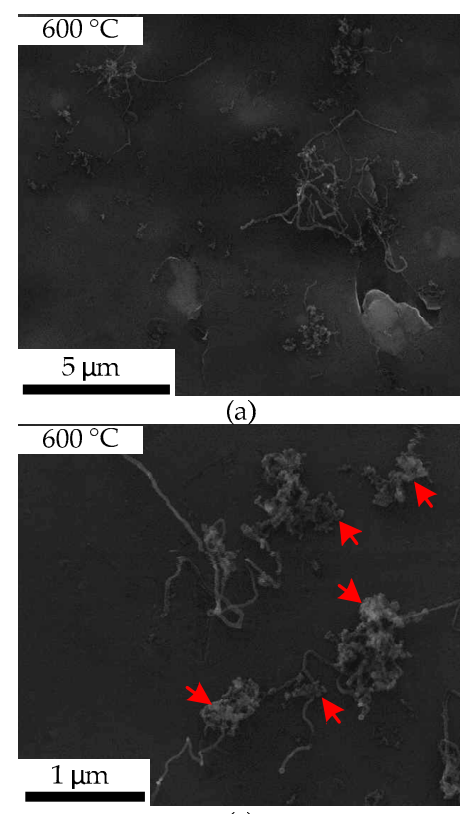

(c)

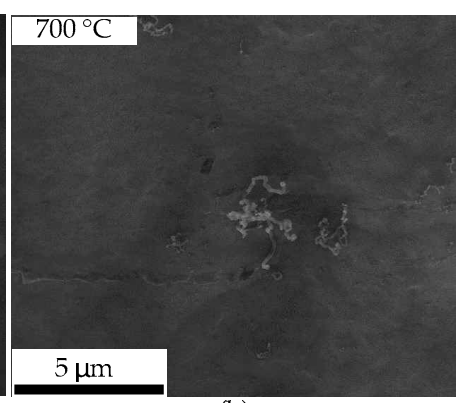

(b)

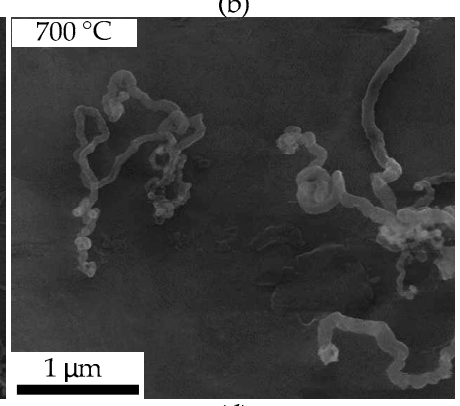

(d)

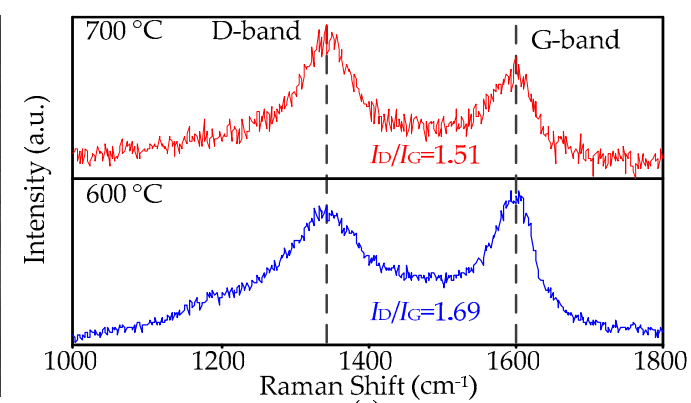

(e)

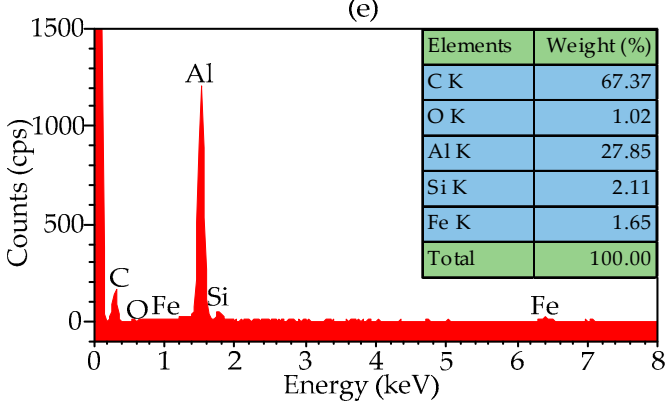

(f)

Figure 9. The SEM micrographs and Raman spectra of the CNTs obtained at 600 and $700{ }^{\circ} \mathrm{C}$ on the aluminum foil treated by $\mathrm{HCl}$. (a,b): low-magnification images; (c,d): high-magnification images; (e): Raman spectra of the CNTs; (f): EDS spectra of the CNTs at $600{ }^{\circ} \mathrm{C}$.

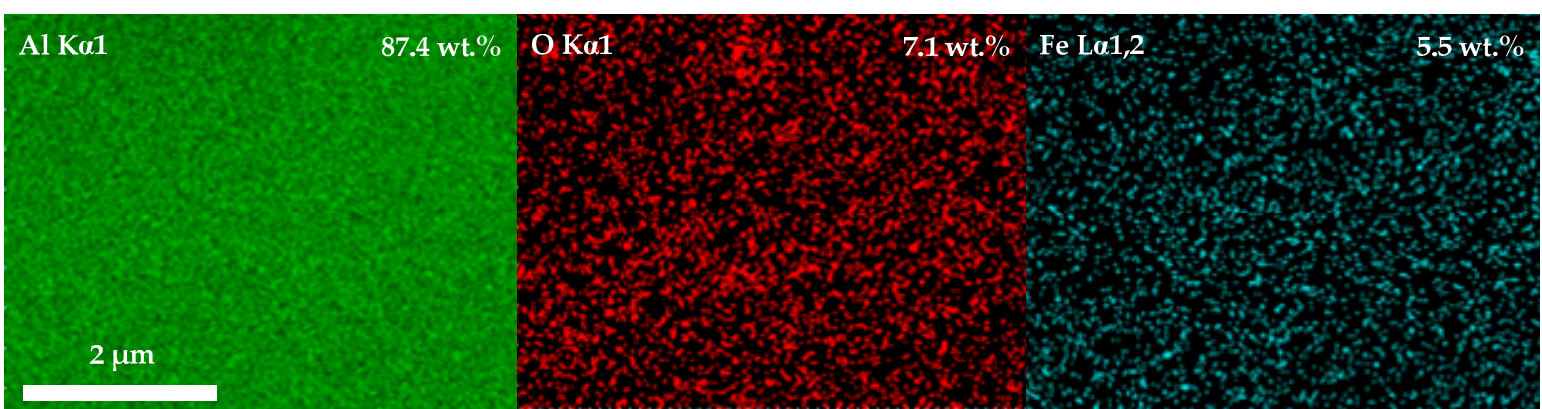

(a)

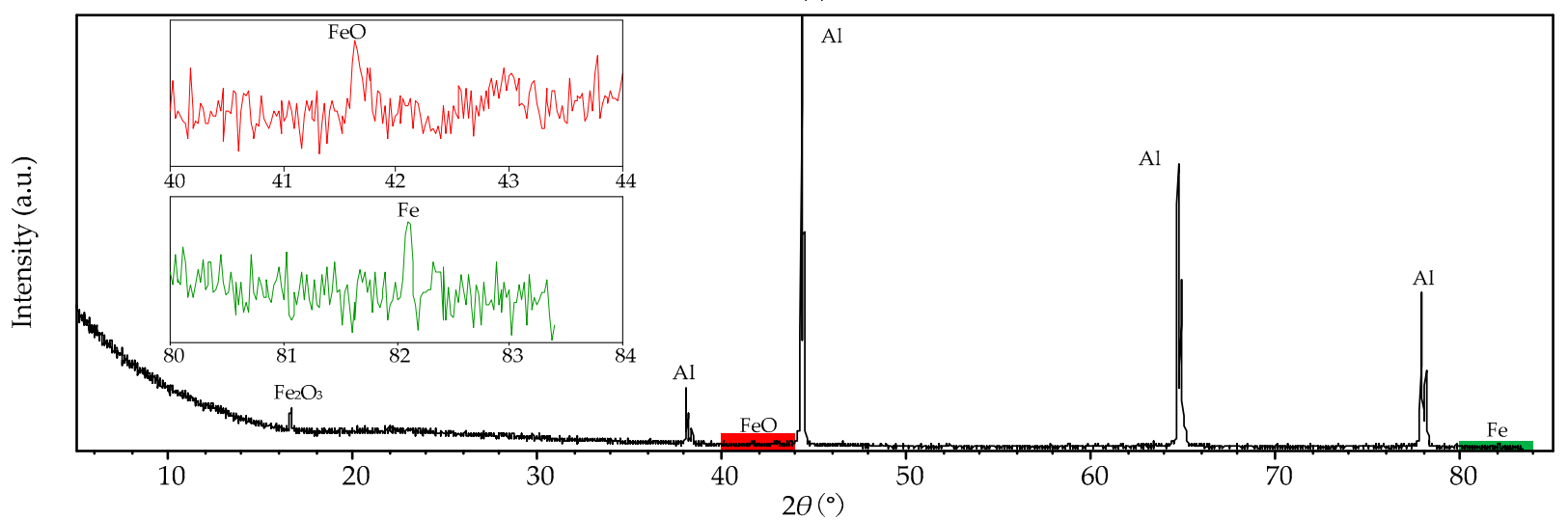

(b)

Figure 10. The EDS mapping and XRD spectra of the original foil after cleaning process, (a): EDS mapping micrograph; (b): XRD spectra.

The $\mathrm{Fe}_{2} \mathrm{O}_{3}$ nanoparticles are reduced to $\mathrm{Fe}$ nanoparticles under the hydrogen atmosphere at high temperatures. Figure 11a shows the XRD spectra of the substrates reduced under hydrogen at $600,700,800$, and $900^{\circ} \mathrm{C}$. When the temperature is $600^{\circ} \mathrm{C}$, the XRD 
spectra show that the iron nanoparticles embedded in the alumina layer are $\mathrm{Fe}_{2} \mathrm{O}_{3}\left(16.2^{\circ}\right.$, $28.2^{\circ}, 46.4^{\circ}$, and $56.0^{\circ}(2 \theta)$ ), which cannot catalyze the growth of CNTs effectively. When the temperature is $700{ }^{\circ} \mathrm{C}$, a trace of $\mathrm{Fe}$ is detected in the XRD spectra, but the $\mathrm{Fe}_{2} \mathrm{O}_{3}$ is still dominant. When the furnace temperature increased to 800 and $900{ }^{\circ} \mathrm{C}$, the XRD shows that the $\mathrm{Fe}_{2} \mathrm{O}_{3}$ nanoparticles are completely reduced into $\mathrm{Fe}$, which could catalyze the growth of CNTs. The CNTs' density at $900{ }^{\circ} \mathrm{C}$ is higher than at $800{ }^{\circ} \mathrm{C}$, is due to the higher activity of Fe nanoparticles at a higher temperature. The EDS mapping micrograph (shown in Figure 11b) shows the distribution of the Fe nanoparticles on the aluminum foil at $900{ }^{\circ} \mathrm{C}$. The reason for the low iron content $(0.6 \mathrm{wt} . \%)$ on the aluminum foil surface is that the iron nanoparticles dispersed in the aluminum foil sink into the molten aluminum at $900{ }^{\circ} \mathrm{C}$. The size and distribution of iron nanoparticles on the aluminum foil surface show no difference with the original one (Figure 10a), indicating that alumina effectively protected the distribution of Fe nanoparticles. The uniform diameter of CNTs contributes to the uniform size of Fe nanoparticles in aluminum.

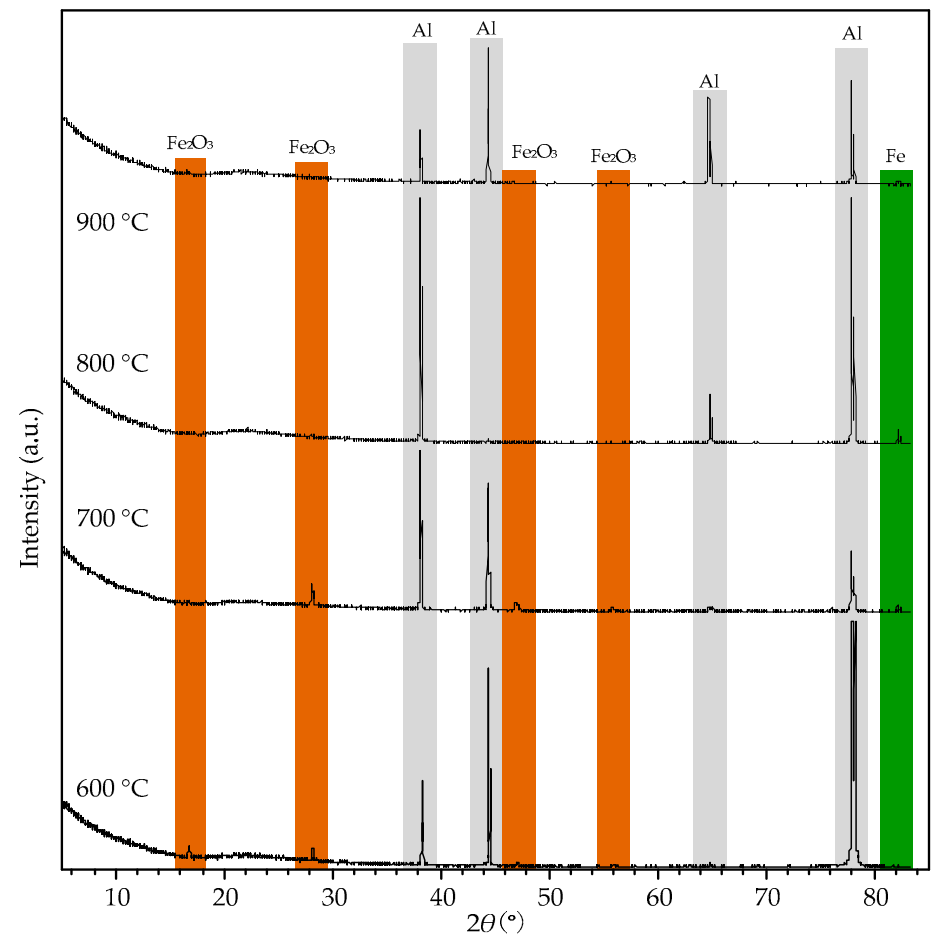

(a)

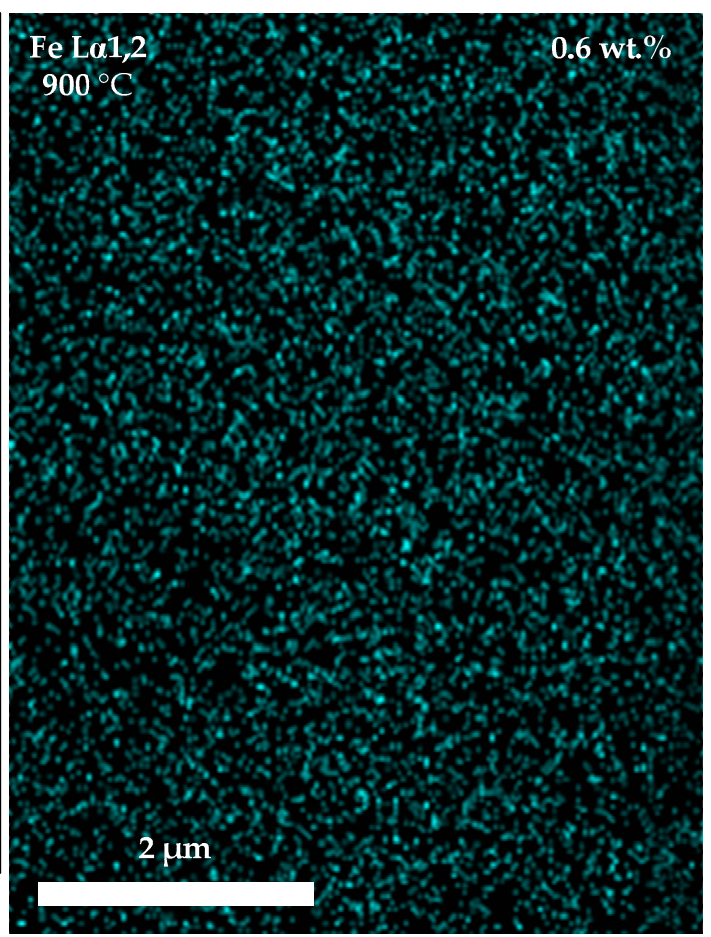

(b)

Figure 11. (a): the XRD spectra of the aluminum foil with alumina film after the reduction process at $600,700,800$, and $900{ }^{\circ} \mathrm{C}$. (b): the EDS mapping micrograph of the substrate at $900{ }^{\circ} \mathrm{C}$.

Figure 12a shows the XRD spectra of the aluminum foil treated by $\mathrm{HCl}$ and reduced at 600,700 , and $800{ }^{\circ} \mathrm{C}$. The spectra show that $\mathrm{Fe}$ and traces of $\mathrm{Fe}_{2} \mathrm{O}_{3}$ were detected at $600{ }^{\circ} \mathrm{C}$, indicating that the iron impurity dispersed in the aluminum foil mainly exists in Fe nanoparticles. $\mathrm{HCl}$ treatment removed the oxide layer from the aluminum foil and exposed the Fe nanoparticles to the carbon-containing groups, resulting in the catalytic growth of CNT on the substrate surface at $600{ }^{\circ} \mathrm{C}$. Figure 12b shows the EDS mapping micrograph of the aluminum foil treated by $\mathrm{HCl}$ and reduced at $700{ }^{\circ} \mathrm{C}$. The result shows some Fe particles with a diameter of 1-2 $\mu \mathrm{m}$ on the aluminum foil surface, and the iron content is only $3.1 \%$. Compared with the original one, the iron particles become larger and fewer. The XRD spectra also show that the amount of $\mathrm{Fe}$ and $\mathrm{Fe}_{2} \mathrm{O}_{3}$ becomes tiny. When the temperature reaches $700{ }^{\circ} \mathrm{C}$ (higher than the melting point of $660^{\circ} \mathrm{C}$ ), the aluminum foil surface partly melts. The iron nanoparticles agglomerate into large particles on the surface and partly sink into the liquid aluminum, resulting in the significant reduction 
and thickening of CNTs. Figure 12 shows that no Fe or $\mathrm{Fe}_{2} \mathrm{O}_{3}$ was detected in the XRD spectra of the substrates reduced at $800{ }^{\circ} \mathrm{C}$. The reason is that the aluminum foil melts entirely at such a high temperature; the liquid aluminum covers the Fe nanoparticles and blocks their contact with the carbon-containing groups, resulting in no CNTs growing on the substrate surface.

CNTs can grow on the aluminum foil edge at $600-900{ }^{\circ} \mathrm{C}$ because the cut section of the aluminum foil exposes the iron nanoparticles. During the heating process, the cut surface would react with the residual oxygen in the tubular furnace to form an oxide layer, and iron nanoparticles were not oxidized due to the presence of hydrogen. Therefore, a layer of alumina film with uniform distribution of iron nanoparticles formed on the edge of the aluminum foil. In the growth process of CNTs, each iron nanoparticle is a seed to grow a carbon nanotube, which results in the CNTs' density showing no difference at all temperatures. The iron catalyst activity increases with the increase of furnace temperature; hence, the diameter of CNTs grown at $900{ }^{\circ} \mathrm{C}$ is thicker than at $800{ }^{\circ} \mathrm{C}$.

Compared to the CNTs grown on the alumina layer, the CNTs grown on the aluminum surface at the same temperature have much amorphous carbon, a less-uniform growth distribution, thicker diameter and shorter length, and are of inferior quality. We can conclude that the alumina layer effectively prevents the catalyst nanoparticles from clustering at high temperatures, making the catalyst nanoparticles distribute evenly on the surface and catalyze the growth of the uniform CNTs.

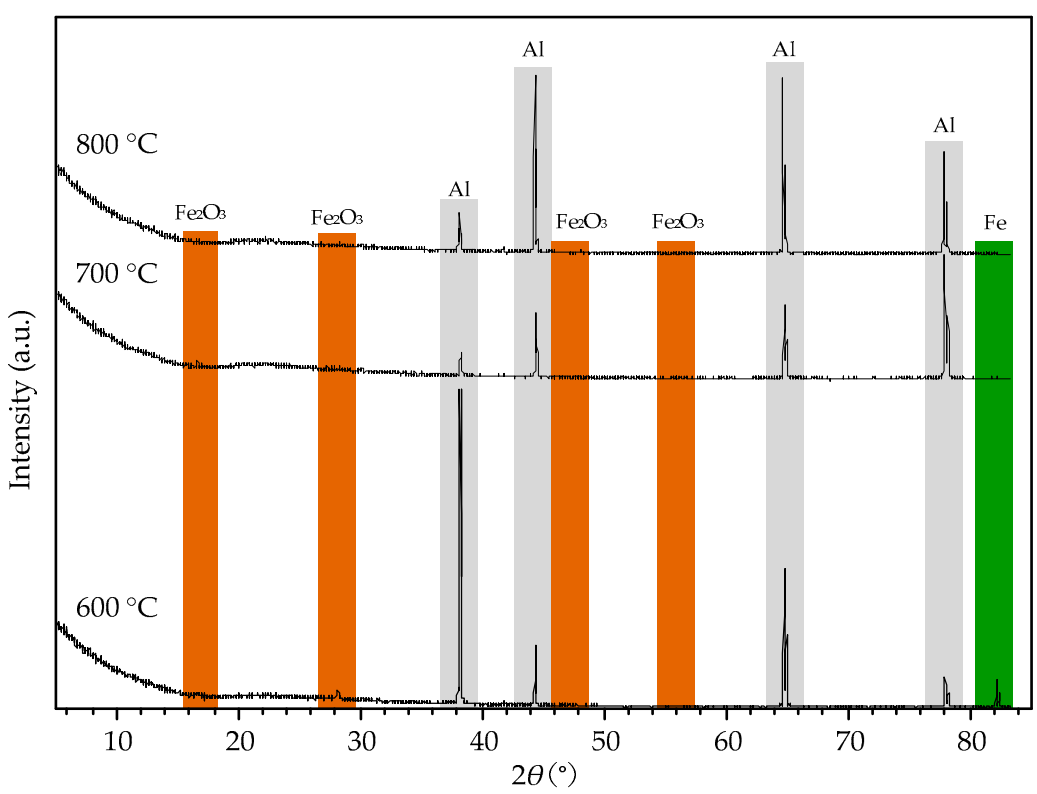

(a)

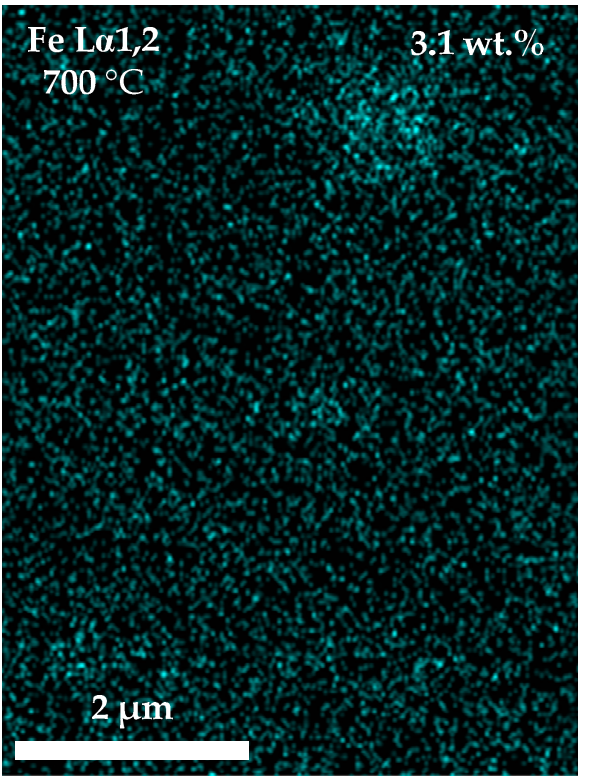

(b)

Figure 12. (a): the XRD spectra of the aluminum foil without alumina film after reduction process at 600,700 , and $800{ }^{\circ} \mathrm{C}$. (b): the EDS mapping micrograph of the substrate after reduction process at $700{ }^{\circ} \mathrm{C}$.

\section{Conclusions}

Herein we report on CNTs' growth on commercial aluminum foils by the AMPCVD using ethanol vapor as the carbon source without additional catalysts at 600, 700, 800, and $900{ }^{\circ} \mathrm{C}$. The iron impurity dispersed in the commercial aluminum foil catalyzed the growth of CNTs. The alumina layer maintained the uniform dispersion and size of iron nanoparticles at high temperatures, making the CNTs grow more uniformly and with less amorphous carbon than on the aluminum surface. The CNTs grown on the alumina layer were multiwalled and had disordered orientation, and their diameter and content increased with the increase in temperature. The defect concentration of the CNTs decreased with the increase in growth temperature. In the AMPCVD synthesis study at 500, 600, 
700,800 , and $900{ }^{\circ} \mathrm{C}$, the optimum synthesis temperature was $900{ }^{\circ} \mathrm{C}$; at the optimum temperature of $900{ }^{\circ} \mathrm{C}$, the highest yield of CNTs was obtained, and the best product crystallinity was produced.

Author Contributions: Conceptualization, L.T. and D.L.; methodology, L.T.; software, D.L.; validation, L.T.; formal analysis, D.L.; investigation, D.L.; resources, L.T.; data curation, L.T.; writingoriginal draft preparation, D.L.; writing-review and editing, L.T.; visualization, D.L.; supervision, L.T.; project administration, L.T.; funding acquisition, L.T. All authors have read and agreed to the published version of the manuscript.

Funding: This work is supported by the National Key Research and Development Program of China (2016YFF0102100) and the Pre-research Project of Civil Aerospace Technology of China (D040109).

Acknowledgments: The high temperature tube furnace and sealing technology are supported by Tianjin ZHONGHUAN Electric Furnace Co. Ltd.

Conflicts of Interest: The authors declare no conflict of interest. The funders had no role in the design of the study; in the collection, analyses, or interpretation of data; in the writing of the manuscript, or in the decision to publish the results.

\section{References}

1. Iijima, S. Helical microtubules of graphitic carbon. Nature 1991, 354, 56-58. [CrossRef]

2. Eres, G.; Puretzky, A.A.; Geohegan, D.B. In situ control of the catalyst efficiency in chemical vapor deposition of vertically aligned carbon nanotubes on pre-deposited metal catalyst film. Appl. Phys. Lett. 2004, 84, 1759-1761. [CrossRef]

3. Zhu, L.W.; Zhou, L.K.; Li, H.X.; Wang, H.F.; Lang, J.P. One-pot growth of free-standing CNTs/TiO2 nanofiber membrane for enhanced photocatalysis. Mater. Lett. 2013, 95, 13-16. [CrossRef]

4. Cheng, J.; Zou, X.P.; Yang, G.Q. Temperature effects on synthesis of multi-walled carbon nanotubes by ethanol catalyst chemical vapor deposition. Adv. Mater. Res. 2010, 123, 799-802. [CrossRef]

5. Li, W.Z.; Xie, S.S.; Qian, L.X.; Chang, B.H.; Zou, B.S. Large-scale synthesis of aligned carbon nanotubes. Science 1996, $274,1701$. [CrossRef]

6. Lee, O.; Jung, J.; Doo, S.; Kim, S.S.; Noh, T.H.; Kim, K.I.; Lim, Y.S. Effects of temperature and catalysts on the synthesis of carbon nanotubes by chemical vapor deposition. Met. Mater. Int. 2010, 16, 663-667. [CrossRef]

7. Youcef, F.; Kihel, M.; Sahli, S.; Raynayd, P. Synthesis of nanopowders in a PECVD reactor from organosilicon precursor. Phosphorus Sulfur 2019, 6, 1-5.

8. Kobashi, K.; Nishimura, K.; Kawate, Y. Synthesis of diamonds by use of microwave plasma chemical-vapor deposition: Morphology and growth of diamond films. Phys. Rev. B Condens. Matter 1988, 38, 4067-4084. [CrossRef]

9. Taylor, A.; Ashcheulov, P.; Hubík, P. Precursor gas composition optimisation for large area boron doped nano-crystalline diamond growth by MW-LA-PECVD. Carbon 2018, 128, 164-171. [CrossRef]

10. Caughman, J.B.O.; Baylor, L.R.; Guillorn, M.A.; Merkulov, V.I.; Lowndes, D.H. Growth of vertically aligned carbon nanofibers by low-pressure inductively coupled plasma-enhanced chemical vapor deposition. Appl. Phys. Lett. 2003, 83, 1207. [CrossRef]

11. Fan, S.S.; Chapline, M.G.; Franklin, N.R.; Tombler, T.W.; Cassell, A.M.; Dai, H.J. Self-oriented regular arrays of carbon nanotubes and their field emission properties. Science 1999, 283, 512-514. [CrossRef] [PubMed]

12. Miao, J.Y.; Hwang, D.H.; Narasimhulu, K.V.; Lin, P.I.; Chen, Y.T.; Lin, S.H.; Hwang, L.P. Synthesis and properties of carbon nanospheres grown by CVD using Kaolin supported transition metal catalysts. Carbon 2004, 42, 813-822. [CrossRef]

13. Dogru, I.B.; Durukan, M.B.; Turel, O.; Unalan, H.E. Flexible supercapacitor electrodes with vertically aligned carbon nanotubes grown on aluminum foils. Prog. Nat. Sci. Mater. Int. 2016, 26, 232-236. [CrossRef]

14. Li, D.; Tong, L.; Gao, B. Synthesis of multiwalled carbon nanotubes on stainless steel by atmospheric pressure microwave plasma chemical vapor deposition. Appl. Sci. 2020, 10, 4468. [CrossRef]

15. Tripathi, P.V.; Durbach, S.; Coville, N.J. Synthesis of multi-walled carbon nanotubes from plastic waste using a stainless-steel CVD reactor as catalyst. Nanomaterials 2017, 7, 284. [CrossRef]

16. Chen, J.; Gao, F.; Zhang, L.; Huang, S. Catalyst-free growth of oriented single-walled carbon nanotubes on mica by ethanol chemical vapor deposition. Mater. Lett. 2009, 63, 721-723. [CrossRef]

17. Li, L.; Wu, Z.; Yuan, S.; Zhang, X.B. Advances and challenges for flexible energy storage and conversion devices and systems. Energy Environ. Sci. 2014, 7, 2101-2122. [CrossRef]

18. Wang, X.; Lu, X.; Liu, B.; Chen, D.; Tong, Y.; Shen, G. Flexible energy-storage devices: Design consideration and recent progress. Adv. Mater. 2014, 26, 4763-4782. [CrossRef]

19. Balamurugan, J.; Nguyen, T.T.; Aravindan, V.; Kim, N.H.; Lee, S.H.; Lee, J.H. All ternary metal selenide nanostructures for high energy flexible charge storage devices. NANO Energy 2019, 65, 103999. [CrossRef]

20. Jung, M.; Kim, H.G.; Lee, J.K.; Joo, O.S.; Mho, S.I. EDLC characteristics of CNTs grown on nanoporous alumina templates. Electrochim. Acta 2004, 50, 857-862. [CrossRef] 
21. Ghai, V.; Chatterjee, K.; Agnihotri, P.K. Vertically aligned carbon nanotubes-coated aluminum foil as flexible supercapacitor electrode for high power applications. Carbon Lett. 2020. [CrossRef]

22. Emmenegger, C.; Bonard, J.M.; Mauron, P.; Sudan, P.; Lepora, A.; Grobety, B.; Zuttel, A.; Schlapbach, L. Synthesis of carbon nanotubes over Fe catalyst on aluminuim and suggested growth mechanism. Carbon 2003, 41, 539-547. [CrossRef]

23. Lin, C.C.; Yang, C.L. Carbon nanotubes grown on nanoporous alumina templates/aluminum foil for electrodes of aluminum electrolytic capacitors. J. Electrochem. Soc. 2010, 157, A237-A241. [CrossRef] 